\title{
Williams Syndrome: The extent of agreement between parent and self report of psychological
}

\author{
Kim Freeman* \\ Tim Ivor Williams ${ }^{\star \star}$ \\ Emily Farran*** \\ Janice Brown ${ }^{\star * \star *}$ \\ * University of Surrey \\ ** University of Reading \& Berkshire \\ Healthcare NHS Trust \\ *** University of Reading \\ **** London South Bank University, London \\ ENGLAND
}

\begin{abstract}
Background and Objectives: People with Williams syndrome (WS) have been reported by their carers to have problems with attention, anxiety and social relationships. People with WS have been shown to report their anxieties. This study extends our knowledge of how people with WS see themselves in terms of behaviour and social relationships.

Methods: A survey using self and parent report forms of the Strengths and Difficulties Questionnaire.

Results: Both parents and individuals with WS $(\mathrm{N}=31)$ reported difficulties in emotional disorder and hyperactivity symptoms and strengths in prosocial behaviours such as altruism and empathy. They disagreed about peer problems.

Conclusions: People with WS understand some but not all of their difficulties. In particular they fail to recognize their social difficulties which may lead them to be vulnerable to exploitation.
\end{abstract}

Received: 3 November 2009

Revised: 4 June 2010

Accepted: 22 June 2010 
Williams syndrome (WS) is a rare genetic disorder ( 1 in 7,500 to 1 in 20,000 live births ${ }^{1,2}$ ) caused by a microdeletion at 7q11.23. The effects include facial dysmorphism, cardiovascular abnormalities and an unusual cognitive and psychological profile ${ }^{3}$. Individuals with WS show mild to moderate levels of learning difficulty (Average IQ 55 range 44-90) ${ }^{4}$ with relative strengths in language and face processing. However, even in these areas, development is not typical ${ }^{5,6}$, and it has been suggested that they have problems integrating global and local levels of visuospatial information (see Farran \& Jarrold $^{7}$, for a review).

In terms of behaviour, individuals with WS are described not only as unusuallywarm, friendly ${ }^{8}$, and empathetic ${ }^{9,10}$, but also as anxious, fearful ${ }^{11-14}$ and hyperactive, with particular problems with distractibility ${ }^{15}$, and a short attention $\operatorname{span}^{16}$. The developmentally pervasive sociability ${ }^{17,18}$ does not however lead to lasting friendships ${ }^{11,19}$. People with WS are unusually inappropriate in conversations ${ }^{8,11,20}$, and have difficulties with concepts of lies and irony ${ }^{21}$. The result is that people with WS may be unusually susceptible to exploitation ${ }^{11}$.

Interventions for the difficulties observed in WS have hardly been investigated. One study has demonstrated the benefits of psychostimulants for hyperactivity ${ }^{22}$. In other populations, it has become clear that psychological interventions offer a useful first option. For instance, there is now a substantial body of research that supports the use of cognitive behaviour therapy for anxiety disorders in children ${ }^{23}$. The effectiveness of many psychological interventions may be compromised by a lack of awareness of their difficulties and unwillingness to change, as demonstrated by the literature on motivational interviewing which helps individuals through stages from lack of awareness of the problem to recognition of the need for change and the actions needed to change $\mathrm{e}^{24,25}$.
With the exception of fears ${ }^{13}$, however, all the reports of psychological problems have been provided by care-givers or professional observers. Therefore, in this study we have sought the views of both carers and people with WS themselves about their needs, on the basis that psychological interventions are generally more successful if the participants recognise that they have a problem and need to change and therefore have the motivation to take part in treatment.

\section{Method}

\section{Ethics}

The project was reviewed according to procedures specified by the University of Reading Ethics and Research Committee and was allowed to proceed. Written or verbal consent was obtained from the participants with WS and written consent was obtained from the carers before filling out the questionnaires. Participants were approached when attending meetings of the Williams Syndrome Foundation or when attending pre-booked sessions for assessment of visuospatial skills. The consent forms were designed to be within the expected reading skill of a primary school child, and if a participant didi not wish to continue with the study they were allowed to leave at any point.

\section{Participants}

The participants were 31 individuals with WS (18 males and 13 females; Mean age = 23.94 years (range 7.67 to 46.41 years)), and their parents, recruited through the Williams Syndrome Foundation UK. All WS participants had been diagnosed phenotypically by qualified clinicians, based on their unique cognitive, behavioural and facial characteristics. Twenty four WS partici- 
pants had also received genetic diagnosis, based on a positive FISH test, which checks for a deletion of the elastin gene on the long arm of chromosome 7 and which has been found to occur in approximately $90 \%$ of individuals with $\mathrm{WS}^{3}$. None of the WS participants had received negative FISH results. Intellectual functioning was not assessed for those participants who were attending Williams Foundation meetings $(\mathrm{N}=17)$. For those who completed the questionnaires while attending prebooked testing, the mean verbal mental age measured on the BPVS was 9 years 5 months (range 4yrs to 13 yrs $1 \mathrm{mth}$ ) and the mean nonverbal mental age was 5 yrs 10 months (range 3 years 7 months to 9 years 2 months).

\section{Measures}

The extended version Strengths and Difficulties Questionnaire (SDQ) ${ }^{26}$ is a well validated, brief behavioural screening questionnaire that can be administered as both self and parental reports. It contains 25 items, in 5 scales (range 0-10); emotional symptoms, conduct problems, hyperactivity, peer problems and pro-social behaviour. Example items from the self rated versions include: "I finish the work I'm doing. My attention is good", "I am nervous in new situations. I easily lose confidence", "I usually share with others (food, games, pens etc.)". The scales can be summed to generate a total difficulties score. The extended version of the SDQ asks whether the respondent thinks the difficulties cause distress and social impairment. Items are scored between 0 (Not at all) to 3 (A great deal). Emerson ${ }^{27}$ has recently demonstrated that the SDQ has good validity when used with populations with a learning disability. Although designed to be used with young people to the age of 17 years, the SDQ was chosen because it is designed to be easy to use, measures both strengths and difficulties and is age independent. Unlike other measures of behaviour it has both carer and self report versions.

\section{Procedure}

WS participants completed the scale themselves, unless they were unable to read them. If the WS participants were unable to read the items, their caregiver read the items out loud to them after the caregiver had already completed the questionnaire. Caregivers were instructed not to influence responses.

\section{Results}

Summary data for parent and self report SDQs of the WS sample are presented in Table 1 alongside normal and borderline ranges and means and standard deviations for typically developing children ${ }^{26}$. Emotional symptoms were reported as a difficulty for individuals with WS by parent and self reports. The "many worries", "many fears" and "clingy in new situations" questions achieved the highest scores. Pro-social behaviour was considered to be a relative strength by all respondents, in the sense that the mean for this sample lay within the normal British range ${ }^{26}$. Conduct disorder was not found to be a primary problem. Both Peer Problems and Hyperactivity were within the abnormal range for typically developing children but this may be expected in individuals with $\mathrm{WS}^{16}$. The only significant correlation with age was found for hyperactivity symptoms which declined with age (parent age correlation $=-0.44, \mathrm{p}<0.005$; self report age correlation $=-0.57, \mathrm{p}<0.005$ ) In order to explore these correlations further we calculated Spearman's rho for each item as filled in by the participants and their par- 
ents. Distractibility as assessed by parents decreased with age $(\delta(31)=-0.54, \mathrm{p}=$ $0.002)$, whereas the ability to reflect before doing something increased $(\delta(31)=0.45, \mathrm{p}$ $=0.012$ ). The participants with WS reported a significant correlation between the ability to reflect before acting $(\delta(31)=0.67, \mathrm{p}<$ $0.001)$ and improved attention with age $(\delta(31)=0.44, \mathrm{p}=0.017)$.

The overall level of agreement between the subscale scores from the SDQ as reported by parents and people with WS was calculated as single measure intraclass correlation coefficients (ICC). To reduce the risk of type 1 errors, Bonferroni's correction was applied and only $\mathrm{p}<0.01$ was accepted as statistically significant. Of the five correlations calculated, three were significant
(Emotional disorder ICC $=0.59, \mathrm{p}<0.001$; Conduct disorder ICC $=0.80, \mathrm{p}<0.001$; Hyperactivity $\mathrm{ICC}=0.45, \mathrm{p}=0.005$ ) and two did not reach statistical significance (Peer problems ICC $=0.3, \mathrm{p}=0.03$; Prosocial behaviour ICC $=0.37, \mathrm{p}=0.02$ ). Using Cicchetti's ${ }^{28}$ criteria, we could say that the correlations for Peer problems and Prosocial behaviour subscales showed poor clinical significance, the Hyperactivity and Emotional disorder subscales showed fair clinical significance whereas the Conduct disorder subscale showed excellent clinical significance. In other words, people with WS agreed well with their caregivers on questions about Hyperactivity, Emotional disorder and Conduct disorder symptoms, but did not agree with their caregivers about their Prosocial behaviour or their Peer problems.

Table 1

Parental and Self Report SDQ mean subscale scores (standard deviations) Williams Syndrome sample and the standardisation sample of British children ${ }^{26}$

\begin{tabular}{|c|c|c|c|c|c|}
\hline $\begin{array}{l}\text { Strength and } \\
\text { Difficulties Subscales }\end{array}$ & $\mathrm{N}$ & $\begin{array}{l}\text { Mean (SD) } \\
\text { subscale score } \\
\text { ssible Range 0-10) }\end{array}$ & $\begin{array}{l}\text { Correlation } \\
\text { with age }\end{array}$ & $\begin{array}{l}\text { Child Normal } \\
\text { (borderline) range }\end{array}$ & $\begin{array}{l}\text { British means } \\
\text { (SD) }\end{array}$ \\
\hline
\end{tabular}

\begin{tabular}{llllll}
\hline $\begin{array}{l}\text { Emotional Symptoms } \\
\quad \text { Parent }\end{array}$ & 31 & $5.19(2.48)$ & $0.23(\mathrm{NS})$ & $0-3(4)$ & $1.9(2.0)$ \\
$\quad$ Self & 31 & $5.45(2.96)$ & $-0.05(\mathrm{NS})$ & $0-5(6)$ & $2.8(2.1)$ \\
\hline $\begin{array}{l}\text { Conduct Problems } \\
\quad \text { Parent }\end{array}$ & 30 & $2.40(2.08)$ & $-0.22(\mathrm{NS})$ & $0-2(3)$ & $1.6(1.7)$ \\
$\quad$ Self & 31 & $2.42(2.46)$ & $-0.15(\mathrm{NS})$ & $0-3(4)$ & $2.2(1.7)$ \\
\hline $\begin{array}{l}\text { Hyperactivity } \\
\quad \text { Parent }\end{array}$ & 31 & $6.45(2.31)$ & $-0.44^{*}$ & $0-5(6)$ & $3.5(2.6)$ \\
$\quad$ Self & 31 & $4.81(2.70)$ & $-0.57^{*}$ & $0-5(6)$ & $3.8(2.2)$ \\
\hline $\begin{array}{l}\text { Peer Problems } \\
\quad \text { Parent }\end{array}$ & 31 & $4.84(1.90)$ & $0.24(\mathrm{NS})$ & $0-2(3)$ & $1.5(1.7)$ \\
$\quad$ Self & 31 & $3.65(1.66)$ & $-0.03(\mathrm{NS})$ & $0-3(4-5)$ & $1.5(1.4)$ \\
\hline $\begin{array}{l}\text { Pro-social Behaviour } \\
\text { Parent }\end{array}$ & 31 & $7.94(2.38)$ & $0.26(\mathrm{NS})$ & $6-10(5)$ & $8.6(1.6)$ \\
$\quad$ Self & 31 & $8.45(1.50)$ & $-0.003(\mathrm{NS})$ & $6-10(5)$ & $8.0(1.7)$ \\
\hline $\begin{array}{l}\text { Impact } \\
\quad \text { Parent }\end{array}$ & 31 & $2.81(2.84)$ & $-0.23(\mathrm{NS})$ & $0(1)$ & $0.4(1.1)$ \\
$\quad$ Self & 31 & $1.81(2.20)$ & $-0.32(\mathrm{NS})$ & $0(1)$ & $0.2(0.8)$ \\
\hline
\end{tabular}

$*=\mathrm{p}<0.005$. 
Table 2

Carer - Self report agreement on Strengths and Difficulties Questionnaire Items from social behaviour subscales

Strength and Difficulties Questionnaire Items

$\mathrm{N} \quad$ Intra class correlation (Number. Brief item name)

coefficient

Peer Problems
6. Solitary
29
0.39
11. One good friend (reverse scored)
$32 \quad 0.29$
14. Liked (reverse scored)

$29 \quad 0.36$
19. Bullied

$280.68 *$
23. Adults
30
0.23

Pro-social Behaviour

$\begin{array}{lll}\text { 1. Considerate } & 32 & 0.10 \\ \text { 4. Shares } & 29 & 0.31 \\ \text { 9. Helpful } & 32 & 0.79^{*} \\ \text { 17. Kind } & 31 & 0.42+ \\ \text { 20. Volunteers } & 30 & 0.32\end{array}$

Hyperactivity

2. Restless

10. Constantly fidgeting

$29 \quad 0.49+$

15. Easily distracted

$30 \quad 0.42+$

21. Thinks things out (reverse scored)

$30 \quad 0.35$

25. Sees tasks through to the end (reverse scored)

$30 \quad 0.35$

Emotional Symptoms
3. Often complains of headaches...
$32 \quad 0.75^{*}$
8. Many worries
$310.58^{*}$
13. Often unhappy

$30 \quad 0.41$
16. Nervous or clingy

$30-0.12$
24. Many fears
30
0.30

\section{Conduct Problems}

5. Often has tempers

7. Generally obedient (reverse scored)

$31-0.75^{*}$

12. Often fights with others

$280.51 *$

18. Often lies or cheats

$26 \quad 0.07$

22. Steals from home or school

$290.66^{*}$

$* \mathrm{p}<0.005$. 
Single measure intraclass correlation coefficients were also used to identify particular items on the Peer Problems and Prosocial subscales where the carers and the self reports differed. Using the Bonferroni correction to reduce type 1 errors on the ten items concerned suggested that only $\mathrm{p}<$ 0.005 should be accepted as statistically significant. Examination of the scores on individual items of the two subscales of the SDQ measuring social interaction skills and difficulties revealed that there were two items with good agreement: being bullied and being helpful (see table 2). In particular parents report more difficulties than WS individuals on the questions having "at least one good friend" "being considerate of others" and "getting on better with adults".

The impact score is a single rating (0-10, low to high) which combines the person's level of difficulties and the effect those difficulties have on the lives of the individuals. Parent reports suggest that WS difficulties have considerable impact on their daily life while individuals with WS report this to a lesser extent than their parents (see table 1). However the intraclass correlation coefficient (ICC $=0.59, \mathrm{p}<0.001)$ suggests that the participants agree quite well. So people with WS who report that their difficulties have most impact, are also reported by their caregivers to have difficulties with the most impact.

\section{Discussion}

People with WS recognise their own strengths and difficulties in many areas of their lives. Both they and their parents know that they have difficulties with Emotional Symptoms and Hyperactivity and no or few Conduct Problems. However, individuals with WS do not report, to the same extent as their parents, the difficulties they have with social relationships (Peer Problems, Prosocial behaviour). In particular the participants with WS agree with their parents about being helpful and being bullied, but did not agree with them about having a good friend, being bullied and whether they got on better with adults than with their peers. They do agree that their hyperactivity symptoms improve with age, as suggested by earlier research ${ }^{11,29}$. This seems to be mostly contributed by an increase in the ability to think before acting although smaller contributions are made by improved distractibility and attention.

To our knowledge this is the first attempt to measure the understanding that people with WS have of their own overall strengths and difficulties and compare their reports to those of their parents. We have shown quite good agreement between parents and those with WS. Although parents often determine the services that people with WS receive, it is important to understand how people with WS make sense of themselves, their lives and their relationships because it may affect their willingness to make changes in their own behaviour ${ }^{24}$.

Although promising, these findings have limitations. Ideally a randomly selected sample of the population with WS would have been recruited. However, the participants were recruited through a parent-run association (Williams Syndrome Foundation UK), which represents most of the families in the UK affected by WS. The extent of bias represented by this sampling is difficult to gauge accurately, however there will also be biases introduced by the perspectives of the informants as has been ably demonstrated by De Los Reyes and Kazdin ${ }^{30}$. The SDQ is a brief behavioural screening questionnaire for 11-16 year old typically developing children, which also appears to be valid when used with populations with 
learning difficulties ${ }^{27}$. Some of the WS participants were outside this age range, however there is no equivalent easy-to-complete measure for older people with parallel forms designed to be used by both carers and affected individuals. Other studies of the psychological difficulties in this population have also used measures designed for typically developing young people ${ }^{10,13}$. However, the results from the use of measures designed solely for carers of learning disabled populations are very similar to ours ${ }^{11,16,29}$, which suggests that our results are unlikely to be an artefact of the use of this measure.

The discrepancy between self and other report is not surprising. Similar findings are common in typically developing populations $^{30}$ and have been found previously in this population ${ }^{13}$. It is difficult for carers to be completely aware of the feelings of their children and equally it is unsurprising that people tend to minimise their behavioural difficulties. The discrepancies between carer and self report might however be due to problems with the use of a self-report scale with people with intellectual disabilities ${ }^{31}$. The SDQ complies with Finlay and Lyons recommendations ${ }^{31}$ in that it contains positively worded questions and modifiers, has simple language and has only three alternatives per question. We would argue however, that the data presented here are similar to those derived from carer only reports using other scales ${ }^{11,16,29}$ and that the validity has been established previously for populations of similar ability ${ }^{27,32}$. Nevertheless, given the concerns raised by Finlay \& Lyons ${ }^{31}$ further studies should be undertaken in which the validity of the SDQ in self-report format is assessed directly. Alternatively as De Los Reyes and Kazdin ${ }^{30}$ point out the difference could simply be due to different perspectives on situations and behaviour.
This has implications for both practice and research. The data suggest that the SDQ can be used for initial identification of problem areas, and areas of disagreement between carer and WS participant. Given the advances in cognitive behavioural techniques for people with a range of intellectual skills (CBT, see e.g. ${ }^{25}$ ), the development of interventions for the anxiety disorders prevalent in WS holds promise. Where there is less agreement about the self reported problems of the population with WS, our data suggests further work to recognise difficulties is necessary. The vulnerability of people with WS to exploitation (e.g. sexual assault ${ }^{11}$ ) indicates that learning more about social relationships is a matter of urgency. Since people with WS recognise many of their problems, it is to be hoped that they will themselves help develop this research area further through collaboration with researchers rather than simply as passive participants.

\section{References}

1. Morris CA, Mervis CB. Williams syndrome. In: Goldstein S, Reynolds CR, eds. Handbook of neurodevelopmental and genetic disorders in children. New York: Guilford; 1999. p. 555-590.

2. Stromme P, Bjornstad PG, Ramstad K. Prevalence estimation of Williams Syndrome. J Child Neurol 2002; 17 : 269-271.

3. Lenhoff HM, Wang PP, Greenberg F, Bellugi U. Williams Syndrome and the Brain. Sci Am 1997; 277(6): 68-73.

4. Bellugi U, Lichtenberger L, Jones W, Lai Z, St. George M. The neurocognitive profile of Williams syndrome: A complex pattern of strengths and weaknesses. J Cog Neuroscience 2000; 12 (Suppl. 1): 7-29.

5. Karmiloff-Smith A, Grant J, Berthoud I, Davies M, Howlin P, Udwin O. Language and Williams syndrome: How intact is "intact". Child Dev 1997, 68(2): 246-262. 
6. Karmiloff-Smith A, Thomas M, Annaz D, Humphreys K, Ewing S, Brace N, et al. Exploring the Williams syndrome face-processing debate: The importance of building developmental trajectories. J Child Psychol Psychiatry 2004; 45(7): 1258-1274.

7. Farran EK, Jarrold C. Visuo-spatial cognition in Williams syndrome: Reviewing and accounting for the strengths and weaknesses in performance. Dev Neuropsychol 2003; 23 (1-2): 173-200.

8. Udwin O, Yule W. A cognitive and behavioural phenotype in Williams Syndrome. J Clin Exp Neuropsychol 1991; 13(2): 232-244.

9. Gosch A, Pankau R. Social-emotional and behavioral adjustment in children with Williams-Beuren syndrome. Am J Med Genet 1994; 53(4): 335-339.

10. Klein-Tasman BP, Mervis CB. Distinctive personality characteristics of 8-, 9-, and 10-year-old children with Williams syndrome. Dev Neuropsychol 2003; 23(1-2): 269-290.

11. Davies M, Udwin O, Howlin P. Adults with Williams syndrome. Preliminary study of social, emotional and behavioural difficulties. Brit J Psychiat 1998; 172: 273-276.

12. Dykens EM, Rosner BA. Refining behavioral phenotypes: personality-motivation in Williams and Prader-Willi syndromes. Am J Ment Retard 1999; 104(2): 158-169.

13. Dykens EM. Anxiety, fears, and phobias in persons with Williams syndrome. Dev Neuropsychol 2003; 23(12): 291-316.

14. Einfeld SL, Tonge BJ, Rees VW. Longitudinal course of behavioral and emotional problems in Williams syndrome. Am J Ment Retard 2001; 106(1): 73-81.

15. Dilts C, Morris CA, Leonard CO. Hypothesis for the Development of a Behavioral Phenotype in Williams Syndrome. Am J Med Genet Suppl 1990; 6: 126-131.

16. Einfeld SL, Tonge BJ, Florio T. Behavioral and emotional disturbance in individuals with Williams syndrome. Am J Ment Retard 1997; 102(1): 45-53.

17. Mervis CB, Klein-Tasman BP. Williams syndrome: Cognition, Personality, and Adaptive Behavior. Mental Retard \& Dev Disabil Res Rev 2000; 6(2): 148-158.

18. Jones W, Bellugi U, Lai Z, Chiles M, Reilly J, Lincoln A, et al. II. Hypersociability in Williams syndrome. J Cog Neurosci 2000; 12(Suppl. 1): 30-46.
19. Rosner BA, Hodapp RM, Fidler DJ, Sagun JN, Dykens EM. Social competence in persons with PraderWilli, Williams, and Down syndromes. J Appl Res Int Dis 2004; 17: 209-217.

20. Laws G, Bishop D. Pragmatic language impairment and social deficits in Williams syndrome: A comparison with Down's syndrome and specific language impairment. Int J Lang Commun Disord 2004; 39(1): 45-64.

21. Sullivan K, Winner E, Tager-Flusberg H. Can Adolescents With Williams Syndrome Tell the Difference Between Lies and Jokes? Dev Neuropsychol 2003;23(1-2): 85-103.

22. Bawden HN, MacDonald G, Shea S. Treatment of children with Williams syndrome with methylphenidate. J Child Neurol 1997; 12(4): 248-252.

23. Cartwright-Hatton S, Roberts C, Chitsabesan P, Fothergill C, Harrington R. Systematic review of the efficacy of cognitive behaviour therapies for childhood and adolescent anxiety disorders. Brit J Clin Psychol 2004; 43: 421-436.

24. Rubak S, Sandbæk A, Lauritzen T, Christensen B. Motivational interviewing: a systematic review and metaanalysis. Brit J Gen Pract 2005; 55: 305-312.

25. Willner P. The effectiveness of psychotherapeutic interventions for people with learning disabilities: a critical overview. J Int Dis Res 2005; 49: 73-85.

26. Goodman R. The extended version of the strengths and difficulties questionnaire as a guide to child psychiatric caseness and consequent burden. J Child Psychol Psychiatry 1999; 40(5): 791-799.

27. Emerson E. Use of the Strengths and Difficulties Questionnaire to assess the mental health needs of children and adolescents with intellectual disabilities. J Intellect Dev Disabil 2005; 30: 14-23.

28. Cicchetti DV. Guidelines, criteria and rules of thumb for evaluating normed and standardized assessment instruments in psychology. Psychol Assess 1994; 6: 284-290.

29. Greer MK, Brown FR, Pai GS, Choudry SH, Klien AJ. Cognitive, Adaptive and Behavioral Characteristics of Williams Syndrome. Am J Med Genet 1997; 74(5): 521-525.

30. De Los Reyes A, Kazdin AE. Informant discrepancies in the assessment of childhood psychopathology: a critical review, theoretical framework, and recommendations for further study. Psychol Bull 2005; 131(4): 483509. 
31. Finlay WM, Lyons E. Methodological issues in interviewing and using self-report questionnaires with people with mental retardation. Psychol Assess 2001; 13(3): 319-335.

32. Muris P, Meesters C, Eijkelenboom A, Vincken M. The self-report version of the Strengths and Difficulties Questionnaire: Its psychometric properties in 8- to 13-year-old nonclinical children. Brit J Clin Psychol 2004; 4: 437-448.
Address for correspondence:

Dr. T.I. Williams

Consultant Clinical Psychologist

3 Craven Road, Reading, RG1 5LR

England

Phone +44(0)1189315800

Fax +44 (0)1189750297

E-mail: sxswiams@reading.ac.uk

Author Note

At the time of this study Kim Freeman was with the Department of Psychology, University of Surrey, England. She is currently with the Department of Psychology, University of Southampton. The work was undertaken as part of a training placement with the School of Psychology and Clinical Language Sciences at the University of Reading, England. Emily Farran is now with the Institute of Education, University of London.

No external bodies provided funding for this study. There were therefore no restrictions on the publication of or access to data from the study. None of the authors have any financial or non-financial conflict of interest in this study. 